\title{
Crack Detection Assisted by an Unmanned Aerial Vehicle for Wonjudaegyo Bridge in Korea ${ }^{+}$
}

\author{
Jae Kang Lee ${ }^{1}$, Min Jun Kim ${ }^{1}$, Jung Ok Kim ${ }^{2}$, Jin Soo Kim ${ }^{3}$, Tri Dev Acharya ${ }^{4}$ and Dong Ha Lee 4,* \\ 1 LX Korea Land and Geospatial Informatix Corporation, Spatial Information Research Institute, \\ Jeonju 54870, Korea; jaekanglee612@gmail.com (J.K.L.); minjoonkim0401@gmail.com (M.J.K.) \\ 2 Institute of Construction and Environmental Engineering, Seoul National University, Seoul 08826, Korea; \\ geostar1@snu.ac.kr \\ 3 National Assembly Research Service, Seoul 07233, Korea; jinsookim@assembly.go.kr \\ 4 Department of Civil Engineering, Kangwon National University, Chuncheon 24341, Korea; \\ tridevacharya@kangwon.ac.kr \\ * Correspondence: geodesy@kangwon.ac.kr; Tel.: +82-33-250-6232 \\ + Presented at the 5th International Electronic Conference on Sensors and Applications, 15-30 November \\ 2018; Available online: https://sciforum.net/conference/ecsa-5.
}

Published: 15 November 2018

\begin{abstract}
Since the 1970s, Korea has achieved exponential economic growth over a short period of time, with a huge amount of infrastructure built. However, 30 years on, this infrastructure is now deteriorating at a rapid pace due to extensive use and climatic factors, raising safety issues in recent years. The current task force faces limitations in monitoring and maintenance due to various reasons: Insufficient budget, increasing number of infrastructure facilities requiring maintenance, shortage of manpower, and a rapidly increasing number of aging infrastructure facilities. To overcome these limitations, a new approach is required that is different from the manual inspection methods under the existing rules and regulations. In this context, this study aimed to explore the efficiency of bridge inspection for cracks by an Unmanned Aerial Vehicle (UAV) that could observe inaccessible areas, could be conveniently and easily controlled, and could offer high economic benefits. A case study of UAV-based crack detection for Wonjudaegyo Bridge, Korea was performed. The results show more effective detection of cracks in the structure than traditional methods.
\end{abstract}

Keywords: structural health monitoring; crack detection; bridge; Korea; UAV; PIX4D

\section{Introduction}

Bridges are an important example of infrastructure. They are directly related to public safety from a socioeconomic perspective, and are critical infrastructure components for transport and logistics, which are integral to economic activities. In Korea, the level of infrastructure safety, as perceived by the population, has significantly dropped in recent years because of natural disasters as well as accidents resulting from human error. Therefore, it is imperative to secure the safety of infrastructures. In fact, public infrastructure safety is a common concern not only in Korea but also in many other countries that have achieved dramatic economic development over a short period of time. In the case of Korea, infrastructure facilities were mainly built during the 1970s and 1980s, when compressed economic development occurred. Infrastructure facilities that were built 30 or more years ago are generally classified as aged infrastructure. A study revealed that aged infrastructure facilities accounted for over $11 \%$ of all infrastructure facilities as of 2017 [1,2]. Therefore, the systematic maintenance, repair, and reinforcement of aged infrastructure facilities, processes which are related to securing the national safety network, are critical problems. So far, good maintenance has kept 
infrastructure facilities free from accidents. However, going forward, the safety of infrastructure may face considerable risk because of the increasing number of aged infrastructure facilities, greater damage inflicted by natural disasters, and inefficient safety and maintenance works. Therefore, to ensure infrastructure safety, which is essential for building a content society, changes must be promptly predicted in the future and new countermeasures must be developed in response [3-5].

Taking the above into consideration for Korea, this study focuses on the investigation of undertaking inspection measures for bridge infrastructure using an Unmanned Aerial Vehicle (UAV). It demonstrates the proposed UAV-based inspection method in a case study of an elevated bridge. This study shows that UAV-based method can easily detects cracks which can save time and cost in the inspection of large numbers of aging bridges in Korea.

\section{Materials and Methods}

\subsection{Case Study}

The bridge selected for the case study was Wonjudaegyo Bridge, located in Panbu-myeon, Wonju-si, Gangwondo Province. It was completed in 1995 and is a steel box girder bridge. Of a total 11 shifts, images were obtained during shifts $2-4$. Figure 1 shows Wonjudaegyo Bridge and Ground Control (GC) points used for this study.

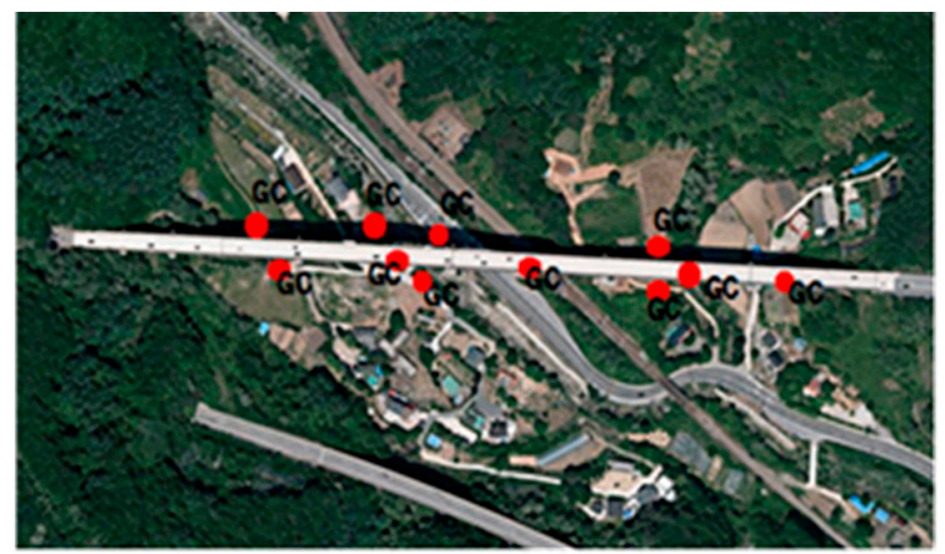

(a)

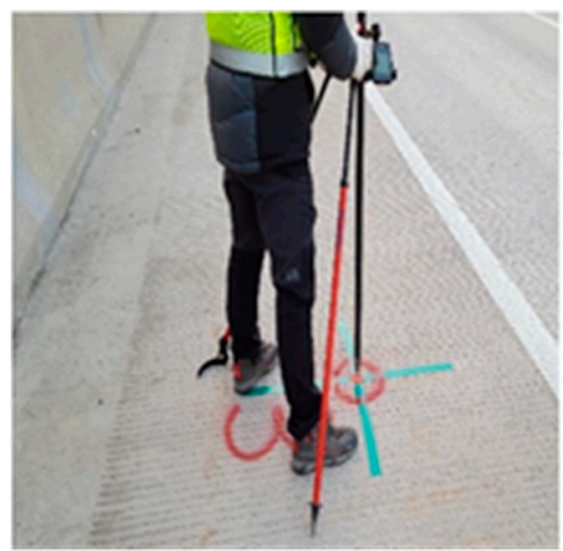

(b)

Figure 1. Wonjudaegyo Bridge, Korea: (a) Aerial view with control point locations; (b) installation of ground control point before flying the UAV.

\subsection{UAV Used}

Table 1 lists the specifications of the UAV used in the study. This UAV is a model designed specifically for maintenance work on bridges and other infrastructure facilities, with an on-top gimbal, and is manufactured by Leica.

The UAV was operated for two days between 20 November and 8 December 2016, beginning at 8 a.m. each morning. The operation hours of the UAV were within the hours of minimal traffic around the bridge and minimal temperature fluctuation due to sunrise, which could result in the creation of air currents. Around 500 short images were obtained during the $2 \mathrm{~h}$ test operation. 
Table 1. Specifications of the UAV used.

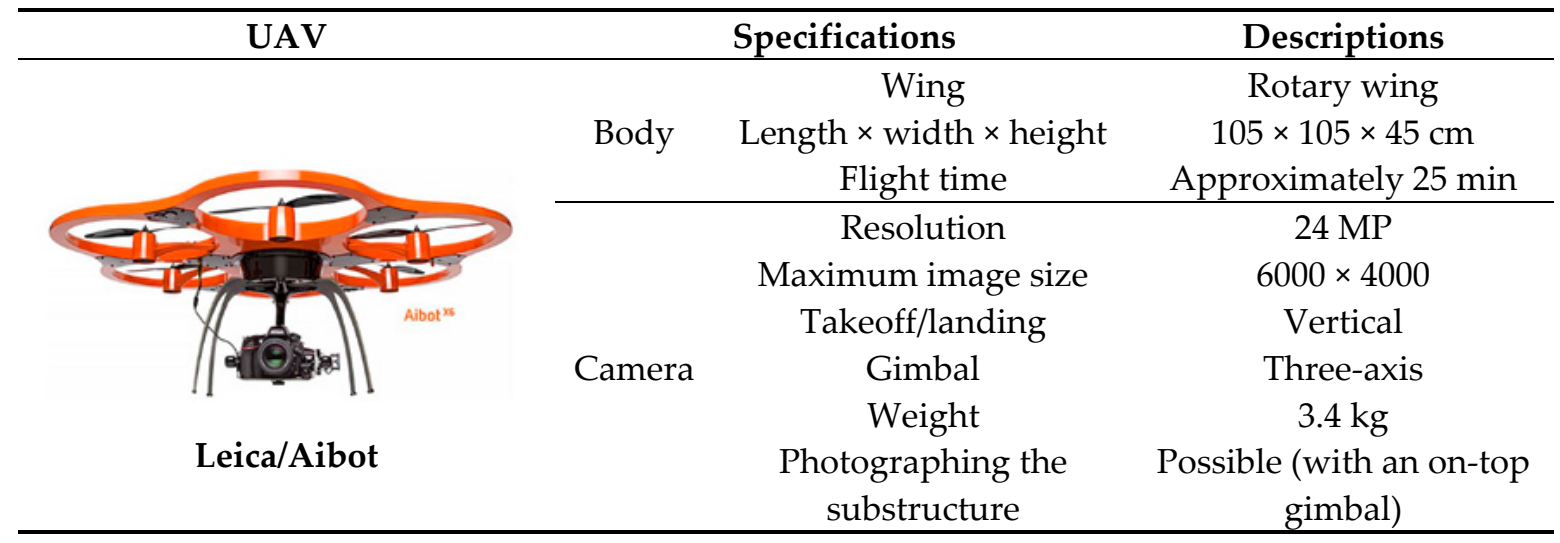

\subsection{Methods}

First, a set of control points were established to register the images, then GPS survey was performed to obtain their precise coordinates. After that, the UAV was flown to take pictures. For processing of the obtained UAV images, PIX4D Mapper software was used. For the coordinate system, the international system of WGS94 coordinates was used, and the variable values of the camera used for recording were considered for the processing. Figure 2 shows a flowchart for the general UAV image processing.

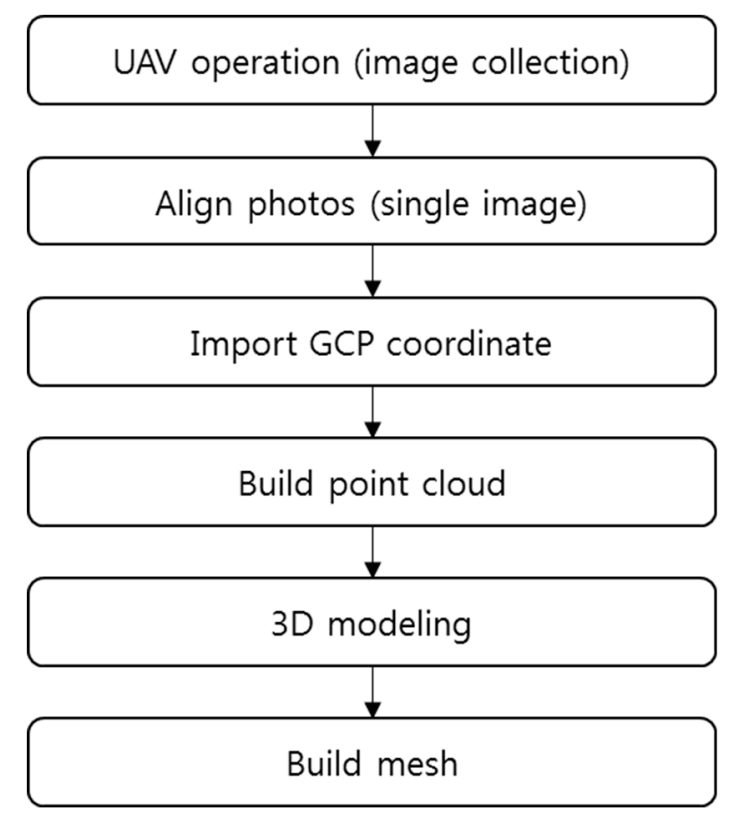

Figure 2. Process for image matching.

\section{Result and Analysis}

After choosing the case study bridge and establishing the control points, flight planning for UAV image capturing was performed. Figure 3 a shows the four strips of flight path planned for the bridge area, and $3 \mathrm{~b}$ shows a sample of an image in PIX4D software. 


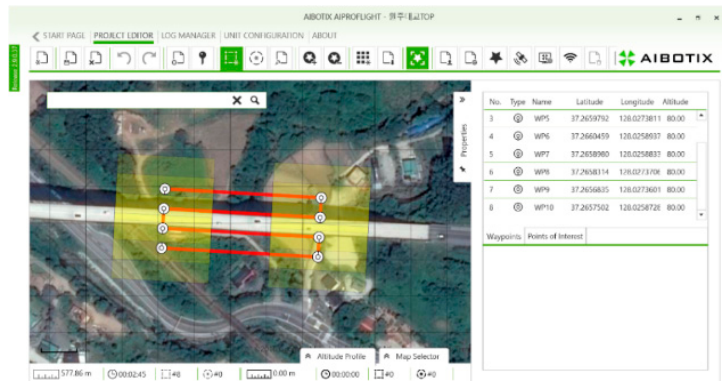

(a)

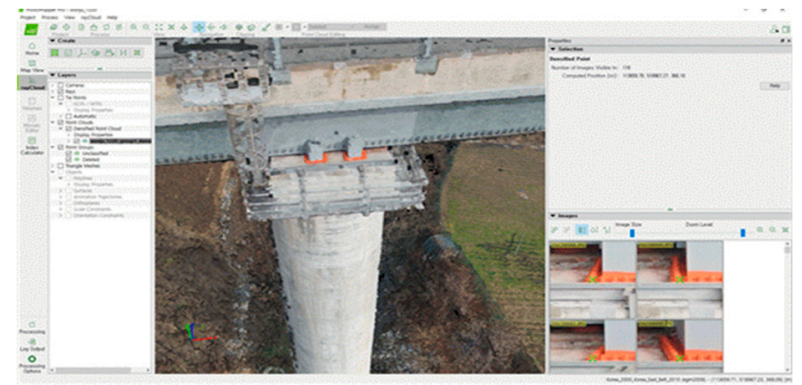

(b)

Figure 3. UAV-based monitoring in Wonjudaegyo Bridge, Korea: (a) Establishing the UAV flight plan; (b) sample image taken by the UAV.

For effective crack detection, image data were extracted from channel L (luminance) and Gaussian adaptive threshold methods were performed, based on which area boundaries of the cracks were extracted. Figure 4 shows each stage of the images taken to extract the cracks in the concrete bridge surface. For comparison of results, the final cracks were overlaid onto the actual image of the surface (Figure $4 \mathrm{~d}$ ). The results were able to detect most of the cracks in UAV image. This shows that a UAV can save cost and time for the efficient health monitoring of structures such as bridges which are expensive to inspect and maintain.

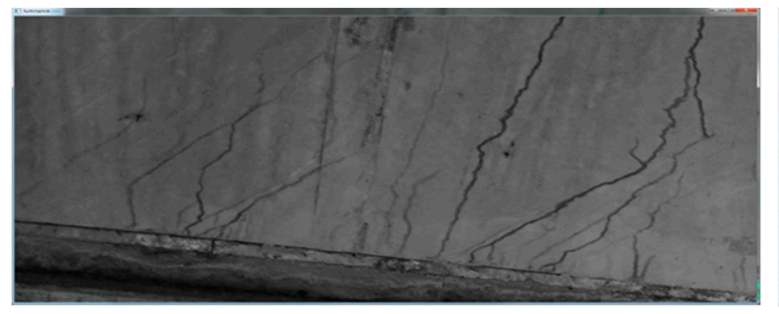

(a)

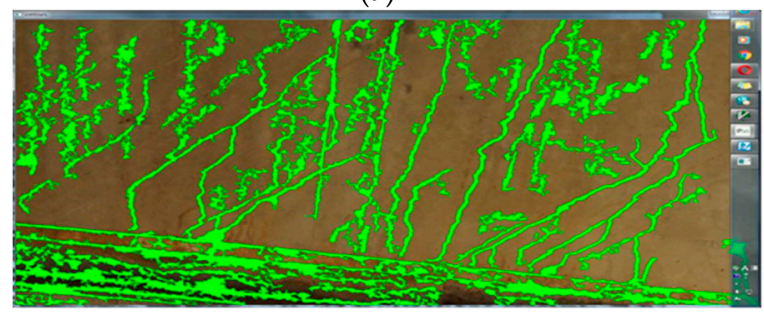

(c)

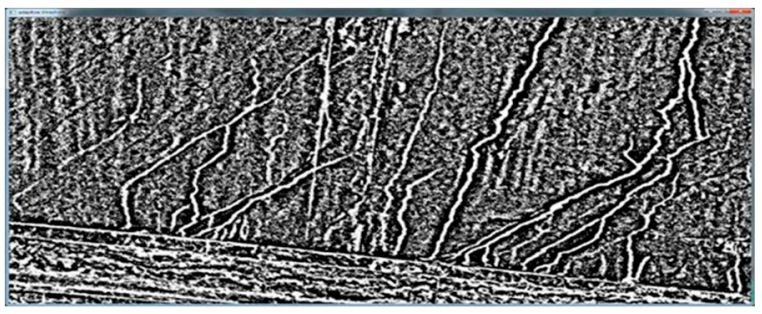

(b)

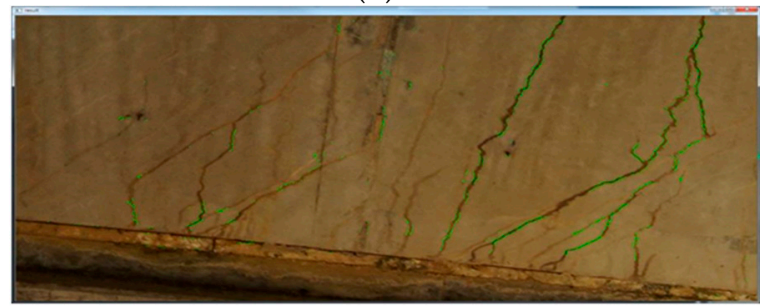

(d)

Figure 4. Results of crack detection in the Wonjudaegyo Bridge, Korea: (a) Data extracted from channel L (luminance); (b) cracks using Gaussian adaptive threshold method; (c) cracks after extracting area boundaries; (d) final cracks overlaid with image.

\section{Conclusions}

This study considered the use of a UAV, which has advantages in terms of economy, convenience, and data acquisition in inaccessible areas, as an alternative to existing methods. We selected Wonjudaegyo Bridge as the case study and used a rotary-wing UAV named Aibotix, which is manufactured by Leica. The images obtained by the UAV were displayed in a 3D viewer after an image-matching process. Thus, the maintenance work could be carried out from any location. Gaussian adaptive method on luminance channel image was applied to inspect the matched images. Crack detection was carried out, and the results were analysed based on the bridge inspection. The proposed UAV-based method was found to be better in terms of cost, time, and convenience.

Conflicts of Interest: The authors declare no conflicts of interest. 


\section{References}

1. Park, K.H.; Sun, J.W. Development of real-time bridge inspection application connected with bridge management system. J. Korea Acad. Ind. Coop. Soc. 2015, 16, 7893-7901, doi:10.5762/KAIS.2015.16.11.7893.

2. Park, K.H.; Sun, J.W. Development of bridge life-cycle management system based on information and communication technology. J. Korea Acad. Ind. Coop. Soc. 2016, 17, 13-20, doi:10.5762/KAIS.2016.17.10.13

3. Metni, N.; Hamel, T. A UAV for bridge inspection: visual servoring control law with orientation limits. Autom. Constr. 2007, 17, 3-10, doi:10.1016/j.autcon.2006.12.010.

4. Oh, J.; Jang, G.; Oh, S.; Lee, J.H.; Yi, B.; Moon, Y.S.; Lee, J.S.; Choi, Y. Bridge inspection robot system with machine vision. Autom. Constr. 2009, 18, 929-941, doi:10.1016/j.autcon.2009.04.003.

5. Mohan, A.; Poobal, S. Crack detection using image processing: a critical review and analysis. Alex. Eng. J. 2018, 57, 787-798, doi:10.1016/j.aej.2017.01.020.

(C) 2019 by the authors. Licensee MDPI, Basel, Switzerland. This article is an open access article distributed under the terms and conditions of the Creative Commons Attribution (CC BY) license (http://creativecommons.org/licenses/by/4.0/). 